\title{
What drives publishing in top management journals: an analysis of language, quantitative competency and financial support
}

\author{
Christian Falaster* \\ Department of Management, \\ Graduate School of Management, \\ Universidade Nove de Julho, \\ Av. Francisco Matarazzo, 912, São Paulo, Brazil \\ E-mail: christianfalaster@gmail.com \\ *Corresponding author

\section{Manuel Portugal Ferreira} \\ Department of Management, \\ Graduate School of Management \\ Universidade Nove de Julho, \\ Av. Francisco Matarazzo, 912, São Paulo, Brazil \\ and \\ Instituto politécnico de Leiria, \\ Leiria, Portugal \\ Email: manuel.portugal.ferreira@gmail.com
}

\begin{abstract}
Publishing in top-level academic journals is both a personal achievement and a crucial requirement in every scholar's career, albeit the institutional demands vary markedly among countries and institutions. In this study, we scrutinise how the effect of a set of factors - expenditure on education, R\&D, English language proficiency and math competency - may influence the likelihood of publishing in top-ranked management journals. We have analysed the entire records of published articles in four top management journals over the past six years (2009-2014). On a sample of 1,322 articles, the results revealed that top level publishing is positively influenced by the national expenditure on $R \& D$ and English proficiency. The quantitative competency proved to have no effect on the ability to publish in top management journals, which is surprising given the current emphasis on quantitative studies. The results are discussed to provide scholars some guidelines to improve their publications in top journals.
\end{abstract}

Keywords: publishing; publication performance; business management research; national factors comparison.

Reference to this paper should be made as follows: Falaster, C. and Ferreira, M.P. (2017) 'What drives publishing in top management journals: an analysis of language, quantitative competency and financial support', Int. J. Bibliometrics in Business and Management, Vol. 1, No. 1, pp.52-69.

Biographical notes: Christian Falaster graduated in Social Communication: Advertising in Universidade Regional de Blumenau (2013). He has a Master's in Management in Universidade Nove de Julho and is pursuing PhD course in Universidade Nove de Julho, where has the main research line in strategy. 


\begin{abstract}
Manuel Portugal Ferreira is a Professor and researcher in the areas of strategic management and international business. He received his $\mathrm{PhD}$ in Business Administration from the David Eccles School of Business, The University of Utah, USA (Fulbright scholar); MBA and MSc from the Portuguese Catholic University, Lisbon, Portugal, an undergraduate in Economics from the School of Economics of the University of Coimbra, Portugal. He is the Director of globADVANTAGE - Center of Research in International Business and Strategy. He is an Associate Editor of the Iberoamerican Journal of Strategic Management.
\end{abstract}

This paper is a revised and expanded version of a paper entitled 'What drives publishing in top management journals: an analysis of language, quantitative competency and financial support' presented at SEMEAD Seminários em Administração, São Paulo, 9-11 November 2015.

\title{
1 Introduction
}

Scholars in some countries succeed more at academic publishing than others. For instance, in management, or business, research there is a long tradition of North American and European authors. The US business schools are currently the benchmark against which many other schools around the globe set the bar. The highest status scientific journals in management are US-based, and are led by US-based editors and reviewers. Examining a sample of 1,322 articles published during the past six years in a sample of top management journals, we found that 1,025 were co-authored by at least one US researcher. And, although some countries such as China, India and South Korea are increasingly raising both the quantity and quality of their publications (Larsen et al., 2008), they are far from scratching the leading position of the US.

There is a preconception that science does not flourish everywhere, or rather, that it flourishes more in some countries than in others (Schøtt, 1987). The extant research on the factors that influence scientific publication has analysed many aspects that may account for the publication differences across countries. For instance, Man et al. (2004) have shown that national factors such as research funding and English proficiency are crucial in determining the scientific output of a country in high impact medical journals. Geuna and Martin (2003) and Leydesdorff and Wagner (2009) compared countries on cost-benefit of research funding. Keller (1985) reviewed the history of scientific discoveries to conclude that math development was crucial for all relevant scientific development over the history. In management discipline, learning and higher education topics are a growing field (Currie and Pandher, 2013), but still require a variety of cross-country analyses, namely to understand the widely diverse publication track records. Scholars from non-developed, non-English-speaking countries often claim that language, lack of funding and a doctoral education poorer on the methodological, especially quantitative, methods are to blame for their lower publication performance.

Hence, the question that warrants our attention, as scholars from many different countries try to make to the top journals, is what drives the academic publishing output of a country and its scholars on top-level management journals. Given the current emphasis 
on the publication record of researchers and especially publishing in top refereed journals, it is relevant to understand at least some of the factors that may drive the publication performance in top tier management journals. As Certo et al. (2010) proposed, scholarly research, perhaps specially when published in top-journals, influences teaching and managerial practice of the discipline, therefore research about publishing in management represents a subject worth studying. In this study we conducted a statistical analysis to examine the role played by English proficiency - the main language for international publication -, quantitative competency and research funding -, on the likelihood of publishing in top-tier management journals.

Top-tier journals are indicators of the research excellence in a discipline (Podsakoff et al., 2005; Certo et al. 2010), thus methodologically, we constructed a database with all articles published in the four top-tier management/business journals assessed by their JCR 2014 impact factors: Academy of Management Annals, Academy of Management Journal, Journal of Management, and Organization Science, published over the six years from 2009 to 2014. On a sample of 1,322 articles published in these journals we collected data on the number of authors, their affiliations and nationality of affiliation. Additional data at the country level was collected from other secondary sources.

The results indicate that English proficiency and research funding were positively related to the number of articles published by the scholars in a country. The quantitative competency, contrary to our expectation, had a no impact on the number of articles published. A possible explanation is that perhaps scholars from countries that excel in math tend to migrate to other areas with higher mathematical content, such as engineering, finance, natural and hard sciences. Alternatively, it may be a function of the field's emphasis on the theoretical contribution that is less amenable to statistically correct papers but that do not have a substantial conceptual contribution. Moreover, the North American and Western European leadership in management journal publications might be related to greater funding of higher education research, natural English proficiency - excellent English proficiency even of non-native speakers - and average levels of math performance.

This study contributes for understanding what factors determine better publication performance in management. As the Academy of Management seeks to enlarge its reach to include scholars in the non-traditional geographies, this is a pertinent matter. We have expanded on the study by Man et al. (2014) on the role of English language proficiency and followed Keller's (1985) suggestion that math may matter, but also included a dimension of national institutional support to research. Hence, the implications extend not only to scholars but also to the regulatory agencies that may gain an insight on how to foster scholars' publication performance. This study mainly seeks to promote a deeper reflection on why some countries are able to make better scholars while others struggle to achieve high levels of publishing. Nonetheless, we ought to understand the institutional incentives in addition to research funding, and inquire what drives, for instance, hiring and promotion in foreign countries, and the individual motivations to conduct research and to publish.

This paper is organised in four sections. First, we discuss the factors we analyse - English proficiency, quantitative competency and research funding - and build three hypotheses. Then, we present the method, including data collection procedures, 
variables and sample. The third section comprises the results. The paper concludes with a broad discussion on how these factors have an important effect on countries' academic development, limitations and future research avenues.

\section{Theory development and hypotheses}

After World War II, research became a fundamental activity for scholars (Teodorescu 2000), the USA took the lead as the world's most prolific scientific power (Larsen et al., 2008), driving much of the scientific efforts and how scientific knowledge would evolve. Only more recently, scholars from other nationalities started to have a more pronounced impact in science, and publishing in top journals. Hence, the American supremacy on the share of scientific publications has decreased from $38 \%$ of all published articles on Web of Science in 1990-1994, to 29\% in more recent years (2008-2012) (Bentley, 2015). Conversely, the European countries, Japan, China and India have significantly raised their share of published articles over the last decade (Larsen et al., 2008).

Countries invest in academic, or knowledge, development because of the potential impact on economic growth; albeit the time lag between research and the economic outcomes can be long (Stephan, 1996). Academic research will likely end up published in journals and patents that may result in innovation and multiple economic outcomes (Furman et al., 2002). In this milieu, many countries institute policies to foster academic development, namely by requiring scholars to conduct research and publish their results in refereed articles. These policies differ from country to country, since the motivators that correlate to productivity are different in each nation (Teodorescu, 2000).

Figure 1 Conceptual model

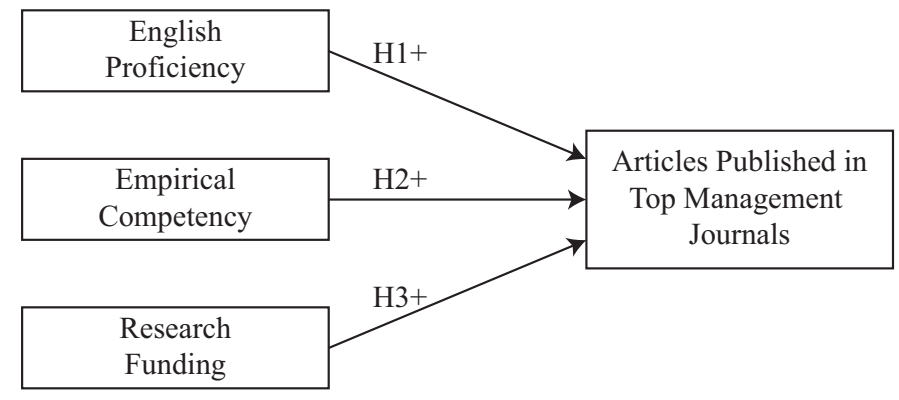

For scholars, publishing is a very serious business. The most critical indicator of research productivity is publication (Ramsden, 1994). Expressions like 'publish or perish' are common (Harzing, 2010) in countries where scholars need to publish in order to survive in academic life. Faculty departments use their researchers' number of publications as a measurement for performance and quality (Ramsden, 1994). In the USA, for instance, the track record of publications is essential for hiring and tenure. Also many universities in the UK have their own listing of which journals matter and scholars must target. Other countries use other listings, such as Brazil that has developed its own listing - the Qualis -, or value publications based on such aspects as the impact factors of the journals. In any instance, regardless of the specific criteria used, the skillset of a researcher is very important for their academic career (Levin and Stephan, 1991), and 
especially publishing in high-impact journals is highly valued by scholars and institutions (Carpenter et al., 2014).

The conceptual model in Figure 1 includes the hypotheses that will be presented.

\subsection{English proficiency}

One of the key factors that determine the scientific output of a country in international (or top-level) journals is the English proficiency of its scholars (Man et al., 2004; Bauwens et al., 2012; Bezzaoucha et al., 2014). English is no doubt the lingua franca for scientific production (Vasconcelos et al., 2007). Being able to read and write in English is a crucial asset for scholars since the majority of the top journals are in English (Ferguson et al., 2009). Moreover, a scholar that does not master the English language will be limited not only in their bibliographic research, but also in the ability to write and submit to these journals. The relevance of the language is especially pertinent to all non-English speakers that acknowledge their disadvantage (Huang, 2010) and take language as the major barrier for academic publication (Bauwens et al., 2012).

As nearly every renowned scientific journal is written in English (Ferguson et al., 2011), scholars must have their papers in English to aim for a top-level publication. While it is difficult to assess each scholar's English proficiency, previous scholars have used nationwide measures resorting to secondary sources of general English skills of the country (Man et al., 2004). The proficiency itself can be defined as the ability that the people of the country have on the English language (Ferguson et al., 2011). Hence, we advance the following hypothesis:

- Hypothesis1. The general level of proficiency in English language of a country will be positively related to the number of articles published in top management journals.

\subsection{Quantitative competency}

Scientific development throughout history has always been preceded by significant mathematical development. Quantitative methods rely on some mathematical rationality which represents an important improvement to scientific method of solving a problem (Keller, 1985). In fact, without endeavouring into the evolution of knowledge, or science, a majority of the articles is theory testing. Scholars thus write a paper with a number of hypotheses that they test empirically, using some form of statistical technique. Hence, while the need for geometrical theorems, formulas and logic mechanics is much clearer in the 'hard sciences', empirical methods using mathematical reasoning are also important in management research.

Quantitative competency, such as math competency, is crucial for an individual's life. While poor mastery of basic math can lead to bad decision-making ability (Schley and Fujita, 2014); affect financial outcomes (Lusardi and Mitchell, 2007) and even health (Lipkus and Peters, 2009). Moreover, the whole development of a person can be affected by their early math skills. Studies show that math skills are related to other cognitive abilities, such as problem solving (Gonzalez-Castro et al., 2014; Decker and Roberts, 2015). In fact, good mathematical learning at a very young age is so important that according to Claessens et al. (2009) it is a good indicator for a person's later academic performance. 
Management research published in top journals has been largely based on quantitative, methods (Phelan et al., 2002; Azorín and Cameron, 2010), possibly because a tendency towards quantitative studies can be good for the discipline because they generate results that can be more easily replicated applied to practice (Perriton, 2009). Some authors have even stated that many business schools are biased in favour of quantitative research (Toubiana, 2014). Phelan et al. (2002), for instance, in an analysis of the articles published in the Strategic Management Journal (SMJ) over the period 1980 to 1999 noted that in the early years of SMJ, the ratio of normal theoretical to empirical quantitative papers was approximately 50:50 but over time the number of empirical quantitative papers published in SMJ greatly increased, reaching a 7:1 ratio to theoretical papers in 1999. As the published articles are becoming increasingly formulaic (Alvesson and Gabriel, 2013), in order to publish a quantitative article in a high impact journal, scholars must be able to conduct increasingly sophisticated quantitative, or statistical, analyses.

In sum, to get published in management, the mastery of quantitative techniques and rationale is a crucial competency. In order to better understand and conduct quantitative research, scholars must have a good understanding of empirical methods, and it is likely that countries that have better teaching systems and have a population capable of mastering the quantitative competency will have greater publication performance. Moreover, similar reasoning applies to publishing theoretical articles and literature reviews, since scholars that do not master quantitative techniques will have a poor understanding of past literature, since theory in business is largely built over quantitative data (Alvesson and Gabriel, 2013). We thus advance the following hypothesis:

- Hypothesis 2. The empirical competency of a country will be positively related to the number of articles published in top management journals.

\subsection{Research funding}

Research funding, especially the expenditures in research and development (R\&D), have been delved upon in cross-country analyses of publication performance. Investment in R\&D and human resources are among the main drivers of countries' knowledge creation process (van Hemert and Nijkamp, 2009). Every country has its own system of research funding and its formula for awarding funds (Liefner, 2003). Countries that spend more in R\&D are more likely to develop patents (Furman et al., 2002) and publish articles (Man et al., 2004). In fact, according to Leydesdorff and Wagner (2009) it is possible to use the relation between R\&D expenditure, especially on Higher Education, and the number of published articles to calculate how much an article can cost for universities and governments.

Examining research funding is important to distinguish the source of the funding since different sources may have different objectives and aim for different outcomes. For instance, businesses expenditure in $R \& D$ is likely to target patents (Leydesdorff and Wagner, 2009) and innovations that may be commercialised to generate a profit. Conversely, the expenditures on academic research support universities, doctoral students and research centres that have less of an applied research perspective. That is, funding of higher education research improves the quality of the research conducted and promotes publications of articles (Man et al., 2004; Leydesdorff and Wagner, 2009). It thus seems reasonable to suggest that researchers in countries with more research funding will have 
more available resources for their research endeavours and therefore perform better and have more top-level articles published.

- Hypothesis 3. The level of research funding in a country will be positively related to the number of articles published in top management journals.

\section{Method}

To conduct this study we first defined the empirical context. Examining the record of publication in top-tier research journals we are observing the top of the cream, the excellence of a discipline (Podsakoff et al., 2005; Certo et al., 2010), and the most desirable achievements. Hence, we selected the top four journals in business management according to their 2014 JCR impact factors (see Table 1). The four journals were: Academy of Management Annals, Academy of Management Journal, Journal of Management, and Organization Science. Jointly these journals published 1,322 articles, excluding editorial comments, book reviews and other items. It is important to note that one of the top-management journals, Academy of Management Review only publishes conceptual papers, thus was excluded from the research since we intend to measure the impact of quantitative empirical competence, a variable that would not have impact on fully conceptual papers which do not use empirical methods.

The choice of four top journals in our analysis is intended to capture only the very edge of management research worldwide. Specifically, we use the four top journals because they represent the top journals (e.g., using JCR - Journal Citation Report) for interdisciplinary research in management, followed in the rank by a set of journals that are known to publish articles dedicated to specific disciplines as are, for instance, the MIS Quarterly, the Strategic Management Journal or the Journal of International Business Studies. Hence, we choose to consider only the top four journals instead of considering more journals and including specific journals or excluding them deliberately.

The second procedure required defining a period. We selected only six years, from 2009 to 2014, since longer time spans could also involve examining the evolution of the journals or changes in editorial policies. Then, we collected data on the articles published in these journals. We examined individually each article and retrieved the journal name, date, title, number of (co)authors, and institutional affiliation of the authors.

\subsection{Variables}

The dependent variable was the number of articles published in the four top management journals over a six-year period (2009-2014) by scholars in each country. We used the main affiliation and mailing address as a proxy to measure country of origin of the scholars, since accurate information on the nationalities of the authors is very scarce and difficult to access. Since many of the articles were written in co-authorship, we considered all co-authors involved. For example, if an article was published by four scholars - two from the USA, one from Brazil and one from Portugal - we counted three nationalities. 
This study used three independent variables: English proficiency, quantitative competency and R\&D funding. To measure the proficiency in English we followed Man et al. (2004) and used the TOEFL English proficiency scores. The data was collected from the TOEFL 2013 reports database (ETS, 2013). We used the general scores rather than the scores on specific abilities (writing, reading, etc.). For native English-speaking countries (USA, Canada, Great Britain, New Zealand, South Africa, Singapore and Australia) we coded English proficiency score as 120, the maximum score for the TOEFL test. It is worth noting that in native English speaking countries it is the foreigners that take the test. Hence, for instance, the English proficiency in the UK was 91 compared to 94 in Sweden.

To assess the competency with empirical, quantitative methodologies, such as statistics, we used a proxy: the OECD math test results, thus depicting math competency. The data for math competency was based on OECD Programme for International Student Assessment (PISA) dataset of 2012. The OECD report provides data for math competency on the high-school level using the performance of 15 year-olds on tests. The OECD (2015) defends the choice of 15 year-old students because they are closer to the end of compulsory school in most of the countries. These tests are made every six years.

Finally, to gauge the availability of research support we measured R\&D funding using the Higher Education Research and Development (HERD) expenditure as proposed by Auranen and Nieminen (2010), Crespi and Geuna (2008) and Leydesdorff and Wagner (2009). The data was collected from the OECD Library database that is publicly available. HERD accounts for R\&D performed in the higher education sector including both publicly and privately funded. It is a good proxy for research funding since it refers to $R \& D$ conducted specifically in higher education sector (mostly universities), which is more likely to result in academic articles, as pointed by Leydesdorff and Wagner (2009). In our calculations, we used the series mean of all HERD conducted during the period 2009-2012.

We also included control variables. We used the countries' GDP, number of researchers, and total population as controls. We controlled for the population size since larger countries are more likely to have more students and researchers, more universities, more research centres, and so forth, and thus have a larger output of articles (Schøtt, 1987; Man et al., 2004; Auranen and Nieminen, 2010). The GDP is used a general measure of a country's wealth and resources available to support, for instance, attending conferences. The number of researchers is a specific measure on the effort placed on R\&D. Data for the controls was retrieved from the World Bank (2015a, 2015b, 2015c).

\subsection{Sample}

The sample comprised 1,322 articles, co-authored by 3,465 scholars from 43 countries. Table 1 describes the sample per journal - including the impact factor of each journal, the number articles, the number of (co)authors and the average number of authors per article on each journal. Organization Science contributed with more articles to the sample (503), while Academy of Management Annals had just 78 articles. The Journal of Management and the Academy of Management Journal have the larger average number of (co)authors per article. 
Table 1 Sample per journal

\begin{tabular}{lcccc}
\hline Item & $\begin{array}{c}\text { Academy of } \\
\text { Management } \\
\text { Annals }\end{array}$ & $\begin{array}{c}\text { Academy of } \\
\text { Management } \\
\text { Journal }\end{array}$ & $\begin{array}{c}\text { Journal of } \\
\text { Management }\end{array}$ & $\begin{array}{c}\text { Organization } \\
\text { Science }\end{array}$ \\
\hline Impact factor (JCR 2014) & 7,333 & 4,974 & 6,862 & 3,807 \\
N. of articles (2009-2014) & 78 & 363 & 378 & 503 \\
N. of (co)authors & 198 & 1,011 & 1,094 & 1,162 \\
Average (co)authors per article & 2.5 & 2.8 & 2.9 & 2.3 \\
\hline
\end{tabular}

Source: Authors' calculations based on research data

Table 2 further describes the dataset, revealing the number of articles published by scholars of each country, the PISA Math competency, HERD, and the TOEFL English proficiency results of each country. The majority of the articles published in the six top-tier management journals were co-authored by North-American scholars $(1,025)$, followed by Canada (138) and the UK (126). On the measure of expenditure on HERD, the USA stands out (60,630 million USD), followed by China (18,699 million USD) and Japan (19,087 million USD). The highest scores in math competency were those of China (613), Singapore (573) and Taiwan (560). On the other hand, the highest scores in TOEFL place the Netherlands (100) and Austria (100) on top, while China (77), United Arab Emirates (76), Turkey (76) and Japan (70) had the lowest scores.

Table 2 Data by country

\begin{tabular}{lcccc}
\hline Country & Articles (a) & $\begin{array}{c}\text { Math competency } \\
\text { (PISA 2012) }\end{array}$ & $\begin{array}{c}\text { English } \\
\text { proficiency } \\
\text { (TOEFL 2013) }\end{array}$ & $\begin{array}{c}\text { HERD (millions } \\
\text { of 2005 USD) }\end{array}$ \\
\hline USA & 1025 & 481 & 120 & $60,630.25$ \\
Canada & 138 & 518 & 120 & $9,265.445$ \\
UK & 126 & 494 & 120 & $10,486.603$ \\
Netherlands & 76 & 523 & 100 & $5,020.075$ \\
China & 73 & 613 & 77 & $18,699.573$ \\
France & 63 & 495 & 88 & $10,980.505$ \\
Australia & 61 & 504 & 120 & $5,446.4$ \\
Singapore & 53 & 573 & 120 & $1,774.4175$ \\
Germany & 37 & 514 & 97 & $16,544.68$ \\
Switzerland & 36 & 531 & 97 & $3,337.83$ \\
Spain & 30 & 484 & 89 & $5,647.3725$ \\
Italy & 25 & 485 & 91 & $7,408.825$ \\
Denmark & 23 & 500 & 98 & $2,097.5925$ \\
\hline
\end{tabular}

Notes: (a) counts the number of nationalities involved. For example, a paper with two authors, one from the US and one from Japan was computed as one time for the US and one for Japan. When data was not available on the newest report, we used the most proximate value. Math competency: OECD PISA report 2012; English proficiency: TOEFL report 2013 (ETS, 2013); HERD data: OECD HERD report 2013.

Source: Authors' calculations based on research data. 
What drives publishing in top management journals

Table 2 Data by country (continued)

\begin{tabular}{|c|c|c|c|c|}
\hline Country & Articles (a) & $\begin{array}{l}\text { Math competency } \\
\quad \text { (PISA 2012) }\end{array}$ & $\begin{array}{c}\text { English } \\
\text { proficiency } \\
\text { (TOEFL 2013) }\end{array}$ & $\begin{array}{c}\text { HERD (millions } \\
\text { of } 2005 \text { USD) }\end{array}$ \\
\hline South Korea & 21 & 554 & 85 & $5,716.175$ \\
\hline Israel & 16 & 466 & 93 & $1,185.1425$ \\
\hline Norway & 14 & 489 & 94 & $1,585.995$ \\
\hline Belgium & 13 & 515 & 97 & $2,123.9375$ \\
\hline Finland & 12 & 519 & 96 & $1,548.5225$ \\
\hline Austria & 8 & 506 & 100 & $2,511.5725$ \\
\hline India & 7 & N/A & 91 & N/A \\
\hline Taiwan & 7 & 560 & 79 & N/A \\
\hline Japan & 7 & 536 & 70 & $19,087.208$ \\
\hline Portugal & 5 & 487 & 95 & $1,583.7475$ \\
\hline U. Arab Emirates & 4 & 423 & 76 & N/A \\
\hline Sweden & 4 & 478 & 94 & $3,443.335$ \\
\hline Brazil & 3 & 391 & 83 & $\mathrm{~N} / \mathrm{A}$ \\
\hline Turkey & 3 & 448 & 76 & $4,862.795$ \\
\hline New Zealand & 3 & 500 & 120 & 556.095 \\
\hline Pakistan & 2 & $\mathrm{~N} / \mathrm{A}$ & 90 & N/A \\
\hline Philippines & 2 & $\mathrm{~N} / \mathrm{A}$ & 89 & N/A \\
\hline Argentina & 2 & 388 & 93 & $1,359.265$ \\
\hline South Africa & 2 & N/A & 120 & $1,247.7567$ \\
\hline Greece & 2 & 453 & 92 & 801.895 \\
\hline Ireland & 2 & 501 & 96 & 798.845 \\
\hline Hungary & 2 & 477 & 92 & 519.73 \\
\hline Slovenia & 2 & 501 & 96 & 162.6725 \\
\hline Bermuda & 1 & N/A & $\mathrm{N} / \mathrm{A}$ & N/A \\
\hline Colombia & 1 & 376 & 81 & N/A \\
\hline Cyprus & 1 & N/A & 84 & $\mathrm{~N} / \mathrm{A}$ \\
\hline Venezuela & 1 & N/A & 83 & N/A \\
\hline Russia & 1 & 482 & 84 & $2,981.6$ \\
\hline Mexico & 1 & 413 & 86 & $2,188.2367$ \\
\hline Luxembourg & 1 & 490 & 97 & 74.2425 \\
\hline
\end{tabular}

Notes: (a) counts the number of nationalities involved. For example, a paper with two authors, one from the US and one from Japan was computed as one time for the US and one for Japan. When data was not available on the newest report, we used the most proximate value. Math competency: OECD PISA report 2012; English proficiency: TOEFL report 2013 (ETS, 2013); HERD data: OECD HERD report 2013.

Source: Authors' calculations based on research data. 
Table 3 Descriptive statistics and correlations

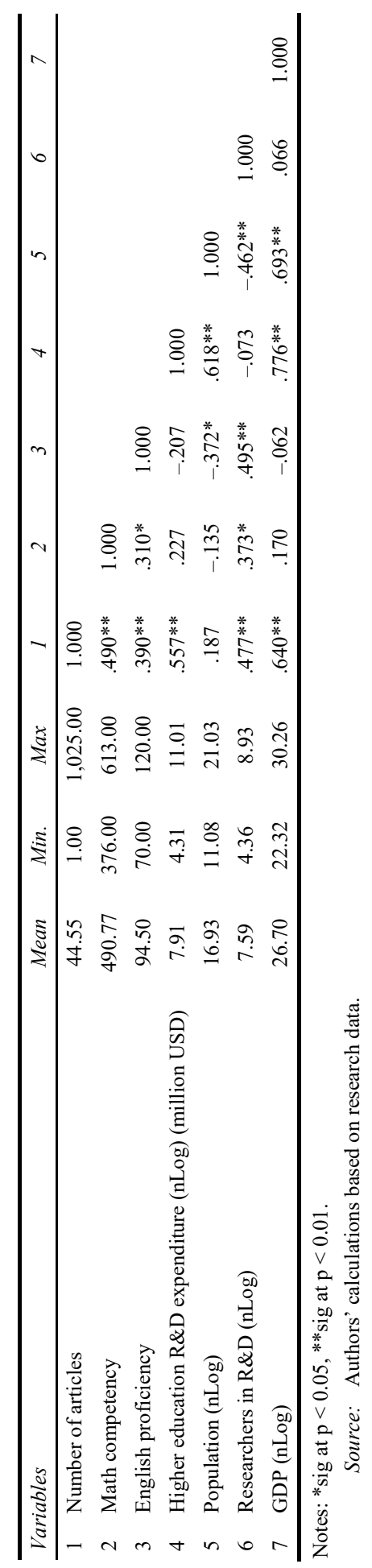




\section{Results}

Table 3 shows the descriptive statistics and correlations. The significant correlations were not so alarmingly high as to raise multicolinearity concerns, and the variance inflation factor (VIF) was below two among the independent variables.

Table 4 Regression results

\begin{tabular}{lccccc}
\hline & Model 1 & Model 2 & Model 3 & Model 4 & Model 5 \\
\hline Population (nLog) & -0.656 & -0.508 & -0.641 & -0.447 & -0.124 \\
GDP (nLog) & $1.006^{*}$ & $0.879^{*}$ & $0.997^{*}$ & 0.592 & 0.24 \\
Researchers in R\&D (nLog) & -0.255 & -0.290 & -0.237 & -0.109 & 0.004 \\
English proficiency & & $0.358^{*}$ & & & $0.400^{* *}$ \\
Math competency & & & -0.030 & & -0.157 \\
Higher education R\&D expenditure (nLog) & & & & 0.31 & $0.431^{* *}$ \\
Model Adjusted R & & & & 0.217 & 0.343 \\
Model x & 0.197 & 0.301 & 0.176 & 3.914 & 4.657 \\
Model ANOVA p-value & 4.424 & 5.518 & 3.249 & 3.914 \\
Std. error expectation & 0.009 & 0.001 & 0.022 & 0.009 & 0.001 \\
$\mathrm{n}$ & 140.237 & 130.815 & 142.001 & 138.418 & 126.798 \\
\hline
\end{tabular}

Notes: Dependent variable is the number of articles published in the four top journals.

${ }^{*}$ sig at $\mathrm{p}<0.05 ;{ }^{*}$ sig at $\mathrm{p}<0.01$. Showing std. beta.

Source: Authors' calculations based on research data

Table 4 includes the regression results testing the hypotheses. Model 1 includes only the control variables. Models 2 to 4 test each hypothesis separately, and model 5 includes all variables. Model 1 tests the effect of English proficiency on the publication output (H1). A positive and significant coefficient $(\beta=0.358, \mathrm{p}<0.050)$ confirms $\mathrm{H} 1$ and denotes that higher proficiency in English is related to the number of articles published in top management journals. The effect of quantitative competency (H2) did not prove significant in model 2, or in model 5. Albeit contrary to what we expected, countries with higher math competency are not more likely to publish in top-tier management journals. Nonetheless, it is important to notice that the countries more relevant in our sample have relatively good scores in the PISA tests. Finally, H3 proposed a positive relation between the support of R\&D efforts, or funding, and the publication record. The coefficient was positive and significant on Model $5(\beta=0.431, \mathrm{p}<0.010)$ thus confirming H3.

\section{Discussion}

We investigated the impact of English proficiency, quantitative competency and research funding on the publication of articles on the top-tier, higher impact factors, business/management journals. These three factors are among the most commonly noted reasons by non-English native scholars from less developed and emerging countries to explain the lower publication records in international peer-reviewed journals. Methodologically we tested three hypotheses using secondary data on the effect of the three variables on the number of papers published in four top management journals. 
We contribute to the discussion of the factors that determine better publication performance in management research. This is an important topic for the academia and some efforts to include a broader audience have been put in place creating, for instance, more dedicated journals. The Academy of Management has organised in 2013 the AOM Africa conference and has several affiliated and associated societies. Other organisations such as the Academy of International Business also seek to gain broader reach beyond the traditional US and European community. Our results further have implications to scholars - namely in understanding the impact of the three variables examined -, and especially to regulatory agencies that have the role of promoting knowledge and the scholars' publication performance. Specifically, these contributions are intended to explore why some countries are able to make scholars with higher publication performance, while others do not achieve high levels of publishing.

The results showed a significant positive effect of English proficiency, corroborating Man et al.'s (2004) finding in health sciences. While this is revealing of an advantage held by English-native speakers, it is possible to overcome such a disadvantage with good education systems, and perhaps good translation. For instance, the non-English native European countries, such as Austria, the Netherlands and Denmark, all have great education systems and are on the top of the list of English proficiency scores. However, other countries with equally excellent education systems, such as Japan and South Korea, do poorly in English proficiency.

The quantitative competency is often taken as a crucial competency of science (Schøtt, 1987). Empirical skills, albeit usually those based on statistical techniques applied to quantitative data, also seem essential to publish in management journals, given the high proportion of articles published that use some form of empirical statistical method (Phelan et al., 2002). While many journals do not have specific guidelines concerning the methodology, the fact is that there is an overwhelming proportion of articles published that are in fact empirical and based on quantitative methods. Our results reveal that quantitative competency, proxied by mathematical competency, is not confirmed to have a positive impact on the publication record. This result is a bit puzzling when considering that it implies that scholars from countries with better quantitative competency are not necessarily more likely to have top-journal articles published. This outcome is contrary to our prediction and warrants additional studies, but a possible explanation may be found in the need for the articles not only to reveal good quantitative methods execution but also a sound conceptual (or theoretical) contribution. It is also possible that scholars from countries with this type of skills may produce studies with great statistical perfectionism, which is one of the key factors for studies not to be rejected (Byrne, 2000). Nonetheless, great empirics alone may not be sufficient to grant publication in top journals. Several scholars have already acknowledged that the main factor for an article to be published is its theoretical contribution (Radford et al., 1999; Turcotte et al., 2004; Clark et al., 2006; Bornmann et al., 2009).

Perhaps an alternative explanation is that countries with high quantitative competency - such as China, Hong Kong, Taiwan and South Korea - also appear to have low English proficiency. English proficiency is significant, weighting more as a factor. Moreover, our data shows that better English proficiency is correlated with good mathematical skills, which we can attribute to a general better educating system.

Institutional support on the form of research funding proved to be a fundamental determinant of a country's publications in top management journals. As hypothesised, research funding plays a positive role on the scientific output, which may not be 
completely surprising, even if we are dealing with a science that does not require huge investments in laboratories or equipment. This result also corroborates van Hemert and Nijkamp's (2009) finding that research funding is the main driver of a country's knowledge creation process.

Expenditure in HERD not only grants a better education system for a country, but also supports researchers in doing a better job at their studies. Databases, data collection, software, language editing services, and many other expenditures are daily costs for universities that require adequate funding. Moreover, countries that spend more on their universities may become more attractive to scholars worldwide, thus attracting the more prolific researchers. Many of these scholars are willing to change country to benefit from better salaries, but also for proper conditions to conduct their studies and advising doctoral students in a munificent academic environment.

This result ought to be examined in the overall academic institutional environment (Auranen and Nieminen, 2010). For instance, it is possible that countries get different outcomes of their funding as Leydesdorff and Wagner (2009) pointed out that a million dollars spent on R\&D in Germany is generally more effective than the same amount spent by the US. In any instance, the North American and Western European supremacy in the number of articles published is likely to be, at least in part, driven by a larger set of institutional factors, beyond merely funding.

\subsection{Limitations and future research avenues}

This study has some limitations that may propel future studies. First, our study was restricted to only the very top journals, as assessed by the JCR 2014 impact factors. Not all research is intended to become a major contribution to theory as the research published at top level journals targets. Also, many countries have their own institutional systems that regulate the publication requirements and what is more or less valued. That is, the incentive systems not always favour publications in top-tier journals. Perhaps extending this study to journals of different ranks we may encounter a different scenario. It would be possible to contrast publications in top versus less top journals, and conduct a more extensive analysis involving other nationalities. This future research is likely to further clarify what drives scholars to publish, including institutional, incentive-based and even individual drivers of publication.

A methodological limitation is on our dependent variable. Data about the actual country of origin of researchers is not easily obtainable, since not even their online university profile covers their place of birth and nationality. This problem may create some bias because some researchers are affiliated to universities in countries other than the ones they were born. This limitation is still a minor issue in our study, since universities would not accept foreign researchers that do not cope with their country standards of English proficiency and math competency, and research funding is more related to the institution of affiliation than to the country of birth of the researcher. Nonetheless, future studies may use the nationality of the authors and compare the findings to observe to what extent it is the country of birth that matters or where an academic career is pursued.

Our independent variables also carry some limitations. Since we have used secondary data from the World Bank and OECD, some variables have minor missing data problems. These problems were solved by mean replacement. A richer and fuller database could bring more solid results to future studies in this subject. 
Another empirical limitation is that we use country level data. Using country level data on English language or mathematical skills provides a reasonable proxy but is not a precise measure. Scholars may stand apart in each country pertaining to the specific competencies we are examining, and probably rank much higher than the broader population surveyed in the instruments we have used. Similarly, it is likely that R\&D funding is unequally distributed across institutions and those more prolific institutions are able to capture the larger part of the resources available. Future studies will need to do a more in-depth analysis, but that may require surveying each individual researcher.

Another limitation pertains to the sample, since we only use published articles and thus fail to have a specific idea on the articles that are rejected. That may be important since we have a built-in assumption that countries that publish little fail more often to overcome successfully the editorial process. That is, their articles are more often rejected. Our study only empirically tests using the number of articles that were accepted and published. Hence, we cannot draw conclusions about the number of articles that are rejected either by editors or reviewers. Future studies could entail examining the articles published and those rejected. That would, of course, require having access to this data from the journals, but could permit examining better the submissions and actual publications, observing the reasons for having he manuscripts rejected. That is, a study on the rejections is likely more clarifying in what drives publication performance.

A possible source of bias is the fact that not every empirical paper is quantitative. Some articles in the sample are empirical but use qualitative methods such as multiple cases studies and ethnography. Studies like these would not be affected by the mathematical competency of the author. Future studies could use information of the type of used methods in order to investigate if researchers in countries with more pronounced mathematical competency have a greater tendency to conduct more quantitative studies than researchers in countries with lower mathematical, or statistical, competency.

Finally, we have only explored data from articles published between 2009 and 2014. Using a longer time span we may delve into the institutional evolutions of the countries are their publication records. That may be especially relevant for countries that are clearly investing more in developing a knowledge producing environment. In Brazil, for instance, the regulatory agency is continuously making substantial adjustments to the system specifying how the doctoral programs are evaluated and the scholars' performance assessed. It has instituted a ranking system of the doctoral programs and evaluates every journal worldwide in an eight points scale. Other countries are implementing different systems and it is interesting to understand what is the impact of those changes on the publication records of scholars.

\section{Final remarks}

We investigated the effects of English proficiency, quantitative competence and research funding on the publication records in top-level management journals. We theorised and tested factors that are often referred to as promoting or, conversely, hindering the ability to publish in top international journals: competency in English, mastery of the quantitative empirical techniques, and the availability of funding for research activities. While some of the results could be expected and for instance, countries that can invest more in educating their citizens and funding research will be more successful publishing in top journals, other results warrant additional studies. A better understanding of the 
factors that may influence the ability to conduct and publish in top journals is relevant for all parties involved, governments that fund research, scholars whose own career depends on their track record of publications and universities that seek accreditation and prestige.

\section{Acknowledgements}

We acknowledge support from CNPq, project number 445928/2014-0.

\section{References}

Alvesson, M. and Gabriel, Y. (2013) 'Beyond formulaic research: in praise of greater diversity in organizational research and publications', Academy of Management Learning and Education, Vol. 12, No. 2, pp.245-263.

Auranen, O. and Nieminen, M. (2010) 'University research funding and publication performance: an international comparison', Research Policy, Vol. 39, No. 6, pp.822-834.

Azorín, J. and Cameron, R. (2010) 'The application of mixed methods in organizational research: a literature review', Electronic Journal of Business Research Methods, Vol. 8, No. 2, pp.95-105.

Bauwens, L., Mion, G. and Thisse, J. (2012) 'The resistible decline of European science', De Boeck Supérieur, Vol. 77, No. 4, pp.5-31.

Bentley, P. (2015) 'Cross-country differences in publishing productivity of academics in research universities', Scientometrics, Vol. 102, No. 1, pp.865-883.

Bezzaoucha, A., Atif, L., Bouamra, A., El Kebboub, A. and Benzerga, M. (2014) 'Algerian medical teachers' research output and its determinants during the 2000-2009 decade', Revue D'épidémiologieet de Santé Publique, Vol. 62, No. 1, pp.33-40.

Bornmann, L., Weymuth, C. and Daniel, H. (2009) 'A content analysis of referees' comments: how do comments on manuscripts rejected by a high-impact journal and later published in either a low- or high-impact journal differ?', Scientometrics, Vol. 83, No. 2, pp.493-506.

Byrne, D. (2000) 'Common reasons for rejecting manuscripts at medical journals: a survey of editors and peer reviewers', Science Editor, Vol. 23', No. 2, pp.39-44.

Carpenter, C., Cone, D. and Sarli, C. (2014) 'Using publication metrics to highlight academic productivity and research impact', Academic Emergency Medicine, Vol. 21, No. 10, pp.1160-1172.

Certo, T., Sirmon, G. and Brymer, A. (2010) 'Competition and scholarly productivity in management: investigating changes in scholarship from 1988 to 2008', Academy of Management Learning \& Education, Vol. 9, No. 4, pp.591-606.

Claessens, A., Duncan, G. and Engel, M. (2009) 'Kindergarten skills and fifth-grade achievement: evidence from the ECLS-K', Economics of Education Review, Vol. 28, No. 4, pp.415-427.

Clark, T., Floyd, S. and Wright, M. (2006) 'On the review process and journal development', Journal of Management Studies, Vol. 43, No. 3, pp.655-664.

Crespi, A. and Geuna, A. (2008) 'An empirical study of scientific production: a cross country analysis, 1981-2002', Research Policy, Vol. 37, No. 4, pp.565-579.

Currie, R. and Pandher, G. (2013) 'Management education journals' rank and tier by active scholars', Academy of Management Learning \& Education, Vol. 12, No. 2, pp.194-218.

Decker, S. and Roberts, A. (2015) 'Specific cognitive predictors of early math problem solving', Psychology In The Schools, Vol. 52, No. 5, pp.477-488.

ETS (2013) TOEFL Test and Score Data Summary 2013 Edition [online] https://www.ets.org/s/toefl/pdf/94227_unlweb.pdf (accessed 17 April 2015). 
Ferguson, G. (2009) 'Issues in researching English as a lingua franca: a conceptual enquiry', International Journal of Applied Linguistics, Vol. 19, No. 2, pp.117-135.

Ferguson, G., Perez-Llantada, C. and Plo, R. (2011) 'English as an international language of scientific publication: a study of attitudes', World Englishes, Vol. 30, No. 1, pp.41-59.

Furman, J., Porter, M. and Stern, S. (2002) 'The determinants of national innovative capacity', Research Policy, Vol. 31, No. 6, pp.899-933.

Geuna, A. and Martin, B. (2003) 'University research evaluation and funding: an international comparison', Minerva, Vol. 41, No. 4, pp.277-304.

Gonzalez-Castro, P., Cueli, M., Cabeza, L. and Rodríguez, C. (2014) 'Improving basic math skills through integrated dynamic representation strategies', Psicothema, Vol. 26, No. 3, pp.378-384.

Harzing, A.W. (2010) The Publish or Perish Book, Tarma Software Research, Melbourne.

Huang, J. (2010) 'Publishing and learning writing for publication in English: perspectives of NNES $\mathrm{PhD}$ students in science', Journal of English for Academic Purposes, Vol. 9, No. 1, pp.33-44.

Keller, A. (1985) 'Mathematics, mechanics and the origins of the culture of mechanical invention', Minerva, Vol. 23, No. 3, pp.348-361.

Larsen, P., Maye, I. and von Ins, M. (2008) 'Scientific output and impact: relative positions of China, Europe, India, Japan and the USA', Collnet Journal of Scientometrics and Information Management, Vol. 2, No. 2, pp.1-10.

Levin, S. and Stephan, P. (1991) 'Research productivity over the life cycle: evidence for academic scientists', The American Economic Review, Vol. 81, No. 1, pp.114-132.

Leydesdorff, L. and Wagner, C. (2009) 'Macro-level indicators of the relations between research funding and research output', Journal of Informetrics, Vol. 3, No. 4, pp.353-362.

Liefner, I. (2003) 'Funding, resource allocation, and performance in higher education systems', Higher Education, Vol. 46, No. 4, pp.469-489.

Lipkus, I. and Peters, E. (2009) 'Understanding the role of numeracy in health: proposed theoretical framework and practical insights', Health Education and Behavior, Vol. 36, No. 6, pp.1065-1081.

Lusardi, A. and Mitchell, O. (2007) 'Baby boomer retirement security: the roles of planning, financial literacy, and housing wealth', Journal of Monetary Economics, Vol. 54, No. 1, pp.205-224.

Man, J., Weinkauf, J., Tsang, M. and Sin, J. (2004) 'Why do some countries publish more than others? An international comparison of research funding, English proficiency and publication output in highly ranked general medical journals', European Journal of Epidemiology, Vol. 19, No. 8, pp.811-817.

OECD (2015) PISA FAQ [online] http://www.oecd.org/pisa/aboutpisa/pisafaq.htm (accessed 17 April 2015).

Perriton, L. (2009) 'A reflection on the significance of numbers', Management Learning, Vol. 40 No. 4, pp.393-399.

Phelan, S., Ferreira, M. and Salvador, R. (2002) 'The first twenty years of the Strategic Management Journal', Strategic Management Journal, Vol. 23, No. 12, pp.1161-1168.

Podsakoff, P., Mackenzie, S., Bachrach, D. and Podsakoff, N. (2005) 'The influence of management journals in the 1980s and 1990s', Strategic Management Journal, Vol. 26, No. 5, pp.473-488.

Radford, D., Smillie, L. and Wilson, R. (1999) 'The criteria used by editors of scientific dental journals in the assessment of manuscripts submitted for publication', British Dental Journal, Vol. 187, No. 7, pp.376-379.

Ramsden, P. (1994) 'Describing and explaining research productivity', Higher Education, Vol. 28, No. 2, pp.207-226. 
Schley, D. and Fujita, K. (2014) 'Seeing the math in the story on how abstraction promotes performance on mathematical word problems', Social Psychological and Personality Science, Vol. 5, No. 8, pp.953-961.

Schøtt, T. (1987) 'Scientific productivity and international integration of small countries: mathematics in Denmark and Israel', Minerva, Vol. 25, Nos. 1-2, pp.3-20.

Stephan, P. (1996) 'The economics of science', Journal of Economic Literature, Vol. 34, No. 3, pp.1199-1235.

Teodorescu, D. (2000) 'Correlates of faculty publication productivity: a cross-national analysis', Higher Education, Vol. 39, No. 2, pp.201-222.

Toubiana, M. (2014) 'Business pedagogy for social justice? An exploratory investigation of business faculty perspectives of social justice in business education', Management Learning, Vol. 45, No. 1, pp.81-102.

Turcotte, C., Drolet, P. and Girard, M. (2004) 'Study design, originality and overall consistency influence acceptance or rejection of manuscripts submitted to the journal', Canadian Journal of Anaesthesia, Vol. 51, No. 6, pp.549-556.

van Hemert, P. and Nijkamp, P. (2010) 'Knowledge investments, business R\&D and innovativeness of countries: a qualitative meta-analytic comparison', Technological Forecasting and Social Change, Vol. 77, No. 3, pp.369-384.

Vasconcelos, S., Sorenson, M. And Leta, J. (2007) 'Scientist-friendly policies for non-native English-speaking authors: timely and welcome', Brazilian Journal of Medical and Biological Research, Vol. 40, No. 6, pp.743-747.

World Bank (2015a) Population by Country Data [online] http://data.worldbank.org/indicator/SP.POP.TOTL (accessed 17 April 2015).

World Bank (2015b) GDP (Current US\$) [online] http://data.worldbank.org/indicator/NY.GDP.MKTP.CD (accessed 17 April 2015).

World Bank (2015c) Researchers in R\&D per Million People [online] $\mathrm{http}: / /$ data.worldbank.org/indicator/SP.POP.SCIE.RD.P6/countries (accessed 17 April 2015). 